\title{
Физиология
}

PHYSIOLOGY

DOI: $10.12731 /$ wsd-2017-1-90-99

УДК 612

\section{ДИНАМИКА МОРФОФУНКЦИОНАЛЬНЫХ ПОКАЗАТЕЛЕЙ МАЛЬЧИКОВ 8-15 ЛЕТ Г. НАБЕРЕЖНЫЕ ЧЕЛНЫ}

\author{
Магсумов Т.А., Смирнова А.В., Хасанова А.Р., \\ Магсумова $P . A$.
}

Целью данной работы было изучение динамики морфофункиионального состояния мальчиков школьного возраста г. Набережные Челны.

Метод или методология проведения работы. По унифицированной антропометрической методике исследованы основные морфофункииональные показатели 800 учащихся общеобразовательных школ 8-15 лет. Анализ проводился по возрастным группам с годовым интервалом, установленным по Мартину.

Результаты. Исследование физического развития мальчиков 8-15 лет г. Набережные Челны показало, что нынешние школьники превосходят школьников 1980-х г2. по основным антропометрическим показателям. В функииональном состоянии сердечно-сосудистой системы выявлены негативные тенденции: более высокие показатели частоты сердечных сокращений и диастолического артериального давления. Во всех возрастных группах отмечено достоверное снижение мымечной силь кистей рук. Жизненная емкость легких у исследуемых в 9 и 10 лет достоверно выме, а в 12-15 - достоверно ниже, чем у их ровесников кония 1980-х г2.

Область применения результатов. Полученные данные могут служить в качестве ориентиров для оченки физического развития отдельных детей или детских коллективов, позволяют разрабатывать систему мероприятий по профилактике отклонений в физическом развитии современных школьников, а также применяться для оценки эффектив- 
ности оздоровительных мероприятий, что, несомненно, будет способствовать укреплению здоровья детского контингента.

Ключевые слова: физическое развитие; мальчики школьного возраста; антропометрия; Набережные Челны.

\section{DYNAMICS OF MORPHOFUNCTIONAL INDICATORS OF BOYS AGED 8-15 Y.O. LIVING IN THE CITY OF NABEREZHNYE CHELNY}

\section{Magsumov T.A., Smirnova A.V., Khasanova A.R., Magsumova R.A.}

The aim of the study is to get an insight into the dynamics of morphofunctional state of school-age boys living in the city of Naberezhnye Chelny.

Methodology of work. The main morphofunctional values of 800 comprehensive school pupils aged 8-15 y.o. were studied using the unified anthropometric technique. The analysis was performed in age groups with a year interval set according to R. Martin.

Results. The physical development study of boys aged 8-15 y.o. living in the city of Naberezhnye Chelny found that present-day pupils outperform the ones of the 1980s on key anthropometric indicators. Certain deterioration signs were revealed in the cardiovascular system functional state, i.e., higher rates of both heart rate and diastolic blood pressure. All age groups showed a significant decrease in hand muscle strength. Lung capacity of the test subjects aged 9-10 y.o. is definitely higher compared to their peers of the late 1980s, whereas lung capacity of the test subjects aged 12-15 y.o. is definitely lower in the same circumstances.

Practical implications. The data obtained may serve as reference points to evaluate physical development of children or groups of children, as well as may allow developing a system of measures to prevent deviations in present-day childrens's physical development, assess the effectiveness of health measures that will undoubtedly contribute to strengthening children's health.

Keywords: physical development; school-age boys; anthropometry; $\mathrm{Na}$ berezhnye Chelny.

Приоритетными задачами современного общества являются создание благоприятных условий для роста и развития, а также укрепление здоровья детей и подростков [8]. 
Наблюдение за ростом и развитием детей и подростков выступает одним из центральных компонентов мониторинга состояния их здоровья. Исследование физического развития в педиатрии и детской гигиене выступает базой для разработки возрастных нормативов учебной, трудовой, спортивной деятельности детей и подростков, осуществления лечебно-профилактических мероприятий и для эколого-гигиенической оценки территории [1].

Исследование физического развития позволяет судить о темпах биологического созревания и гармоничности морфофункционального статуca, как отдельного индивидуума, так и детской популяции в целом [8].

Проведено исследование физического развития 800 мальчиков 8-15 лет г. Набережные Челны в сравнительном аспекте. Программа исследования включала антропометрию ведущих показателей физического развития - длины (см), массы тела (кг), окружности грудной клетки (ОГК, см), а так же исследование функциональных показателей дыхательной (жизненная емкость легких (ЖЕЛ, мл), сердечно-сосудистой (артериальное давление (АД, мм рт ст) и частота сердечных сокращений (ЧСС, уд/ мин), и мышечной систем (сила кистей рук (МС, кг) стандартным инструментарием по общепринятой унифицированной методике [10].

Программа обработки полученного эмпирического материала содержала установление календарного (хронологического) возраста детей на время исследования. Формирование возрастных групп шло с годовым интервалом, установленным по Мартину (в каждой по 100 школьников): к 8 -летним относили детей в возрасте от 7 лет 6 мес. до 8 лет 5 мес. 29 дней и т.д. По данным медицинского осмотра все школьники отнесены к группе практически здоровых детей.

Сравнение физического развития мальчиков проводилось с аналогичными данными, полученными в ходе исследования физического развития детей г. Набережные Челны, проведенного в 1986 г. по идентичной, строго унифицированной программе [9]. Результаты исследования представлены в таблице 1.

Обработка результатов осуществлялась по общепринятой вариационно-статистической методике с использованием t-критерия коэффициента Стьюдента ( $\mathrm{M} \pm \mathrm{m}, \sigma \pm \mathrm{m})$.

Основные морфофункциональные показатели обследованных групп представлены в табл. 1.

Рассматривая физическое развитие мальчиков в сравнении с 1980-ми гг. выявили, достоверно ( $<<0,05)$, более высокие значения по основным со- 
матометрическим показателям у современных школьников во все изучаемые возрастные периоды, кроме мальчиков 10 лет по длине тела. Так, исследованные 8-летние мальчики выше своих ровесников прошлого столетия в среднем на 3,5 см, в 9 лет - на 6 см, в 10 - на 2,7, в $11-4,6$ см, в 12 - на 6,1 см, в 13 лет - на 5,3 см, в 14 и 15 лет соответственно - на 5,7 и 8,1 см. Средние значения массы тела у обследованных школьников превышают таковые в 8 лет на 3,5 кг, в 9-10 лет - на 5,2 кг, в 11 - 6 кг, в 12 лет - на 8,3 кг, в 13 лет - на 5,6 кг, в 14 и 15 лет соответственно - на 6,1 и 9,3 кг. Различия по окружности грудной клетки у 8-летних мальчиков конца 1980-х гг. и современных школьников составили в среднем 2,5 см, в 9-10 лет -3,7, в $11-4,2$ см, в $12-6,0$ см, в 13 лет - 4,2 см, в 14 и 15 лет соответственно - 3,8 и 5,6 см. Максимальные различия по соматометрическим показателям у мальчиков 2014 и 1986 гг. исследования выявлены в возрасте 9, 11, 12 и 15 лет.

Полученные в ходе исследования данные об изменении тотальных размеров тела детей указывают на позитивные сдвиги в физическом развитии, а также, вполне возможно, на «новый виток» процесса акселерации.

Функциональное состояние дыхательной, сердечно-сосудистой и мышечной систем отражает уровень адаптационно-приспособительных реакций организма.

Проведенный анализ показал, что у современных детей всех исследованных групп средние величины систолического артериального давления ниже, а у 15-летних мальчиков достоверно $(\mathrm{p}<0,05)$ выше, чем у их сверстников в конце 1980-х гг. Средние величины диастолического артериального давления у нынешних школьников выше, чем у их ровесников прошлого века, различия достоверны $(\mathrm{p}<0,05)$ в 9, 10, 11,12 и 15 лет.

Исследование хронотропной функции сердца в состоянии покоя выявило более высокую частоту сердцебиений у изучаемых детей, по сравнению с их сверстниками конца XX века. Достоверные различия $(\mathrm{p}<0,05)$ по ЧСС выявлены у мальчиков в 9, 11-15 лет. С возрастом указанные различия нарастают: в 9 лет ЧСС больше на 5 уд/мин, в 11 - на 8, в 12 лет на 9, в 13 - на 11, в 14 и 15 лет соответственно - на 16 и 17 уд/мин. У исследованных мальчиков не наблюдается возрастного снижения ЧСС. Е.С. Богомолова с соавторами [2] полагают, что тенденция к тахикардии у современных школьников свидетельствует о растущем напряжении адаптационных процессов роста и созревания учащихся в социально-экономических условиях жизни и условиях внутришкольной среды: высокая 
учебная нагрузка и низкая мотивация здорового образа жизни приводят к гипокинезии, а на фоне нарушений в питании, как следствие избыточная масса тела, ожирение и синдром вегетативной дисфункции.

Для характеристики функциональных возможностей исследуемых, проведена кистевая динамометрия. Выявлено достоверное отставание $(\mathrm{p}<0,05)$ по мышечной силе рук и силовому индексу исследованных мальчиков всех возрастных групп по сравнению с их ровесниками конца 1980х годов. Мышечная сила мальчиков 8-12 лет в среднем на 6 кг меньше, чем у их сверстников, а в 15 лет - на 9,1 кг. Нами в ряде случаев отмечались такие низкие значения по МС рук как 5,5 кг. Выявленные различия более выражены по мышечной силе правой руки. С возрастом указанная тенденция усиливается.

Полученные результаты по снижению силовых показателей детей и подростков в XXI в. согласуются с данными многих исследователей [2; $3 ; 4 ; 5 ; 6 ; 7 ; 11 ; 12]$. Снижение силовых возможностей связывается ими с отсутствием у детей интереса к занятию спортом и малоподвижным образом жизни, обусловленными в том числе обширным внедрением в частную жизнь средств коммуникации, компьютеров, телевизоров, а также нарушением питания. Аналогичные результаты получены и по жизненной емкости легких: достоверно более низкие значения $(\mathrm{p}<0,05)$ во всех исследованных возрастных группах у современных старшеклассников.

Фактические данные жизненной емкости легких у школьников 9 и 10 лет достоверно $(\mathrm{p}<0,05)$ выше, чем у их ровесников прошлых десятилетий. Полученные результаты согласуются с литературными данными по оценке силовых возможностей и жизненной емкости легких у современных детей $[3 ; 4 ; 8]$. Некоторые исследователи расценивают достоверное увеличение жизненной емкости легких как компенсаторно-адаптационный ответ на хроническую гипоксию жителей промышленных городов [8].

Таким образом, проведенное исследование позволило изучить динамику основных показателей физического развития мальчиков школьного возраста г. Набережные Челны за последние тридцать лет. Полученные данные указывают на позитивные тенденции в физическом развитии, и, вероятно, на «новый виток» процесса акселерации. Тенденции роста и развития подрастающего поколения г. Набережные Челны в целом отражают общие закономерности, присущие детям и подросткам больших городов нашей страны. 
Таблицуа 1.

Основные морфофункциональные показатели учащихся 8-15 лет (M \pm m)

\begin{tabular}{|c|c|c|c|c|c|c|c|c|c|}
\hline \multirow{2}{*}{ 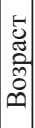 } & \multirow{2}{*}{$\begin{array}{c}\text { Длина } \\
\text { тела, см }\end{array}$} & \multirow[b]{2}{*}{$\begin{array}{c}\text { Macca, } \\
\text { кг }\end{array}$} & \multirow{2}{*}{$\begin{array}{c}\text { ОКГ, } \\
\text { См }\end{array}$} & \multicolumn{2}{|c|}{ АД, мм. рт. ст. } & \multirow{2}{*}{$\begin{array}{c}\text { ЧСС, уд/ } \\
\text { мин }\end{array}$} & \multicolumn{2}{|c|}{ Динамометрия, кг } & \multirow[b]{2}{*}{ ЖЕЛ, л } \\
\hline & & & & $\begin{array}{c}\text { Систоли- } \\
\text { ческое }\end{array}$ & $\begin{array}{c}\text { Диасто- } \\
\text { лическое }\end{array}$ & & $\begin{array}{l}\text { левая } \\
\text { кисть }\end{array}$ & $\begin{array}{c}\text { правая } \\
\text { кисть }\end{array}$ & \\
\hline 8 & $128,59 \pm 0,53 *$ & $27,60 \pm 0,47 *$ & $63,32 \pm 0,47^{*}$ & $99,98 \pm 1,50$ & $=1,18$ & $91,52 \pm 1,70$ & $8,85 \pm 0,21 *$ & $9,85 \pm 0,24 *$ & $1,13 \pm 0,02$ \\
\hline 9 & $136,14 \pm 0,63^{*}$ & $32,66 \pm 0,81^{*}$ & $66,74 \pm 0,61 *$ & $100,78 \pm 1,58$ & $64,78 \pm 1,39 *$ & $91,16 \pm 1,21 *$ & $10,59 \pm 0,26^{*}$ & $11,51 \pm 0,29 *$ & $1,63 \pm 0,03^{*}$ \\
\hline 10 & $137,94 \pm 1,36$ & $35,56 \pm 0,83^{*}$ & $68,86 \pm 0,74 *$ & $102,37 \pm 1,99$ & $66,03 \pm 1,09 *$ & $85,70 \pm 1,38$ & $12,56 \pm 0,31 *$ & $13,80 \pm 0,35^{*}$ & $1,81 \pm 0,03 *$ \\
\hline 11 & $145,17 \pm 0,69 *$ & $38,85 \pm 0,85^{*}$ & $71,06 \pm 0,74 *$ & $108,55 \pm 1,39$ & $65,85 \pm 0,87 *$ & $90,80 \pm 1,44 *$ & $14,25 \pm 0,36^{*}$ & $15,67 \pm 0,38^{*}$ & $2,00 \pm 0,03$ \\
\hline 12 & $151,10 \pm 0,84 *$ & $44,91 \pm 0,92 *$ & $75,28 \pm 0,69^{*}$ & $109,51 \pm 1,46$ & $70,48 \pm 1,50 *$ & $87,71 \pm 1,59 *$ & $17,38 \pm 0,35 *$ & $18,91 \pm 0,36^{*}$ & $2,05 \pm 0,03 *$ \\
\hline 13 & $156,99 \pm 0,73 *$ & $47,54 \pm 0,84 *$ & $76,61 \pm 0,59 *$ & $112,49 \pm 1,34$ & $68,60 \pm 1,08$ & $86,62 \pm 1,46^{*}$ & $19,36 \pm 0,45^{*}$ & $20,94 \pm 0,45^{*}$ & $2,10 \pm 0,05^{*}$ \\
\hline 14 & $163,74 \pm 0,90 *$ & $53,30 \pm 0,99 *$ & $80,00 \pm 0,67 *$ & $119,83 \pm 1,56$ & $71,40 \pm 1,08$ & $90,09 \pm 1,75^{*}$ & $24,18 \pm 0,73 *$ & $26,12 \pm 0,76^{*}$ & $2,27 \pm 0,05^{*}$ \\
\hline 15 & $170,91 \pm 1,21 *$ & $60,99 \pm 1,22 *$ & $84,88 \pm 0,78^{*}$ & $124,79 \pm 1,57^{*}$ & $72,86 \pm 1,13 *$ & $89,28 \pm 1,66^{*}$ & $29,69 \pm 0,66 *$ & $31,64 \pm 0,68 *$ & $2,64 \pm 0,07 *$ \\
\hline
\end{tabular}

Примечание: * - достоверные различия $(\mathrm{p}<0,05)$ с данными 1986 г.

\section{Список литературы}

1. Баранов А.А., Кучма В.Р., Скоблина Н.А. Физическое развитие детей и подростков на рубеже тысячелетий. М.: Научный центр здоровья детей PAMH, 2008. 216 c.

2. Богомолова Е.С, Матвеева Н.А., Кузмичев Ю.Г., Бадеева Т.В., Ашина М.В., Леонов А.В., Платонова Т.В. Региональный мониторинг роста и развития школьников г. Нижнего Новгорода: опыт и перспективы // Физическое развитие детей и подростков Российской Федерации. Сб. матлов (выпуск VI) / Под ред. акад. РАН и РАМН А.А. Баранова, член-корр. РАМН В.Р. Кучмы. М.: Издательство «ПедиатрЂ», 2013. С. 44-63.

3. Криволапчук И.А. Возрастная динамика и адаптационные изменения функционального состояния детей 5-14 лет под влиянием занятий физическими упражнениями: автореф. дисс. ... д-ра биол. наук. М., 2008. 49 c.

4. Кучма В.Р., Скоблина Н.А., Платонова А.Г. Физическое развитие московских и киевских школьников // Гигиена и санитария. 2011. №1. С. 75-78.

5. Лобачева А.В., Исламова Е.А., Фурман Г.Л., Свищева Е.М. Рациональное питание и его роль в формировании здорового образа жизни // Материалы науч.-практ. конф. с междунар. участием «Фармакотерапия и диетология в педиатрии». Казань, 2011. 114 с. 
6. Мишкова Т.А. Морфофункциональные особенности и адаптационные возможности современной студенческой молодежи в связи с оценкой физического развития: автореф. дисс. ... канд. биол. наук. М., 2010. $24 \mathrm{c}$.

7. Москаленко О.Л., Пуликов А.С. Состояние физического развития юношей гг. Красноярска и Железногорска // В мире научных открытий. 2016. № 11 (83). С. 120-127.

8. Онищенко Г.Г. Роль государственной санитарно-эпидемиологической службы России в защите здоровья населения // Здравоохранение Российской Федерации. 2013. № 2. С. 3-10.

9. Оценка физического развития детей Республики Татарстан / Сост.: Н.Х. Амиров, Х.А. Бекмансуров, А.Н. Галиуллин, 3.Т. Шарафутдинов, А.Х. Яруллин. Казань-Набережные Челны, 1993. 232 с.

10. Ставицкая А.Б., Арон Д.И. Методика исследования физического развития детей и подростков. М.: Медгиз, 1959. 75 с., 3 л. табл. : ил.

11. Физическое развитие детей и подростков Российской Федерации. Сб. матлов (выпуск VI) / Под ред. акад. РАН и РАМН А.А. Баранова, член-корр. РАМН В.Р. Кучмы. - М.: Издательство «ПедиатрЪ», 2013. 192 с.

12. Чагаева Н.В., Попова И.В., Токарев А.Н., Кашин А.В., Беляков В.А. Сравнительная характеристика физиометрических показателей физического развития школьников // Гигиена и санитария. 2011. № 2. С. 72-75.

\section{References}

1. Baranov A.A., Kuchma V.R., Skoblina N.A. Fizicheskoe razvitie detey i podrostkov na rubezhe tysyacheletiy [Physical development of children and adolescents at the turn of the Millennium]. Moscow: Nauchnyy tsentr zdorov'ya detey RAMN, 2008. $216 \mathrm{p}$.

2. Bogomolova E.S, Matveeva N.A., Kuzmichev Yu.G., Badeeva T.V., Ashina M.V., Leonov A.V., Platonova T.V. Regional'nyy monitoring rosta i razvitiya shkol'nikov g. Nizhnego Novgoroda: opyt i perspektivy [Regional monitoring of growth and development of schoolchildren in Nizhny Novgorod: experience and prospects]. Fizicheskoe razvitie detey i podrostkov Rossiyskoy Federatsii. Sb. mat-lov (vypusk VI) [Physical development of children and adolescents of the Russian Federation. The collection of materials (issue VI)] / Pod red. akad. RAN i RAMN A.A. Baranova, chlen-korr. RAMN V.R. Kuchmy. Moscow: Izdatel'stvo «Pediatr», 2013, pp. 44-63.

3. Krivolapchuk I.A. Vozrastnaya dinamika i adaptatsionnye izmeneniya funktsional'nogo sostoyaniya detey 5-14 let pod vliyaniem zanyatiy fizicheskimi up- 
razhneniyami: avtoref. diss. ... d-ra biol. nauk [Age dynamics and adaptable changes of a functional state of children of 5-14 years under the influence of physical exercises: thesis of Dr. Biol. Sciences]. Moscow, 2008. 49 p.

4. Kuchma V.R., Skoblina N.A., Platonova A.G. Fizicheskoe razvitie moskovskikh i kievskikh shkol'nikov [Physical development of Moscow and Kiev schoolchildren]. Gigiena i sanitariya, 2011, no 1, pp. 75-78.

5. Lobacheva A.V., Islamova E.A., Furman G.L., Svishcheva E.M. Ratsional'noe pitanie i ego rol' $\mathrm{v}$ formirovanii zdorovogo obraza zhizni [Rational nutrition and its role in the formation of a healthy lifestyle]. Materialy nauch.-prakt. konf. s mezhdunar. uchastiem "Farmakoterapiya $i$ dietologiya $v$ pediatrii» [Materials of scientific-practical conference with international participation "Pharmacotherapy and dietology in Pediatrics"]. Kazan', 2011. 114 p.

6. Mishkova T.A. Morfofunktsional'nye osobennosti i adaptatsionnye vozmozhnosti sovremennoy studencheskoy molodezhi $v$ svyazi s otsenkoy fizicheskogo razvitiya: avtoref. diss. ... kand. biol. nauk [Morpho-functional peculiarities and adaptability of modern student youth in connection with the assessment of physical development: thesis of candidate of Biol. Sciences]. Moscow, 2010. $24 \mathrm{p}$.

7. Moskalenko O.L., Pulikov A.S. Sostoyanie fizicheskogo razvitiya yunoshey gg. Krasnoyarska i Zheleznogorska [The state of physical development of the young men in the city of Krasnoyarsk and Zheleznogorsk]. V mire nauchnykh otkrytiy, 2016, no 11 (83), pp. 120-127.

8. Onishchenko G.G. Rol' gosudarstvennoy sanitarno-epidemiologicheskoy sluzhby Rossii $v$ zashchite zdorov'ya naseleniya [The role of the state sanitary and epidemiological service of Russia in the protection of the health of the population]. Zdravookhranenie Rossiyskoy Federatsii, 2013, no 2, pp. 3-10.

9. Otsenka fizicheskogo razvitiya detey Respubliki Tatarstan [Assessment of physical development of children of the Republic of Tatarstan] / N.Kh. Amirov, Kh.A. Bekmansurov, A.N. Galiullin, Z.T. Sharafutdinov, A.Kh. Yarullin. Kazan' - Naberezhnye Chelny, 1993. 232 p.

10. Stavitskaya A.B., Aron D.I. Metodika issledovaniya fizicheskogo razvitiya detey i podrostkov [Methods of research of physical development of children and adolescents]. Moscow: Medgiz, 1959. 75 p.

11. Fizicheskoe razvitie detey i podrostkov Rossiyskoy Federatsii. Sb. mat-lov (vypusk VI) [Physical development of children and adolescents of the Russian Federation. The collection of materials (issue VI)] / Pod red. akad. RAN i RAMN A.A. Baranova, chlen-korr. RAMN V.R. Kuchmy. Moscow: Izdatel'stvo «Pediatr», 2013. $192 \mathrm{p}$. 
12. Chagaeva N.V., Popova I.V., Tokarev A.N., Kashin A.V., Belyakov V.A. Sravnitel'naya kharakteristika fiziometricheskikh pokazateley fizicheskogo razvitiya shkol'nikov [Comparative characteristics visiometrics indicators of physical development of schoolchildren]. Gigiena i sanitariya, 2011, no 2, pp. 72-75.

\section{ДАННЫЕ ОБ АВТОРАХ}

Магсумов Тимур Альбертович, кандидат исторических наук, доцент, старший научный сотрудник лаборатории мировых цивилизаций, доцент кафедры истории и методики ее преподавания

Международный сетевой центр фундаментальных и прикладных исследований; Набережночелнинский государственный педагогический университет

ул. Горького, 89а, офис 4, г. Сочи, 354000, Российская Федерация; ул. Низаметдинова, 28, г. Набережные Челны, 423806, Российская Федераичя

nabonid1@yandex.ru

Смирнова Алла Витальевна, кандидат биологических наук, доцент кафедры биологии и методики ее преподавания

Набережночелнинский государственный педагогический универcumem

ул. Низаметдинова, 28, г. Набережные Челны, 423806, Российская Федераичя

a11a05@bk.ru

Хасанова Альфия Радифовна, кандидат биологических наук, доцент, доцент кафедры биологии и методики ее преподавания

Набережночелнинский государственный педагогический универcumem

ул. Низаметдинова, 28, г. Набережные Челны, 423806, Российская Федераичия

a.khasanova@mail.ru

Магсумова Раиса Альбертовна, интерн кафедры педиатрии и неонатологии

Ижевская государственная медиичнская академия ул. Коммунаров, 281, г. Июеевкк, 426034, Российская Федерация nabonid1@yandex.ru 


\section{DATA ABOUT THE AUTHORS}

Magsumov Timur Al'bertovich, Ph.D. in History, Associate Professor, Senior Researcher of the Laboratory for World Civilizations; Associate Professor of History and its Teaching Methods Department International Network Center for Fundamental and Applied Research; Naberezhnye Chelny State Pedagogical University

89a, Gorkogo Str., office 4, Sochi, 354000, Russian Federation; 28, Nisametdinova Str., Naberezhnie Chelny, 423806, Russian Federation nabonid1@yandex.ru

SPIN-code: 1329-1458

ORCID: 0000-0003-0117-7513

ResearcherID: I-5300-2013

Scopus Author ID: 55799874500

Smirnova Alla Vital'evna, Ph.D. in Biology, Associate Professor of Biology and its Teaching Methods Department Naberezhnye Chelny State Pedagogical University 28, Nisametdinova Str., Naberezhnie Chelny, 423806, Russian Federation a11a05@bk.ru SPIN-code: 7676-6363

Khasanova Al'fiya Radifovna, Ph.D. in Biology, Associate Professor, Associate Professor of Biology and its Teaching Methods Department Naberezhnye Chelny State Pedagogical University 28, Nisametdinova Str., Naberezhnie Chelny, 423806, Russian Federation a.khasanova@mail.ru SPIN-code: 2889-0070

Magsumova Raisa Al'bertovna, Intern of Department of Pediatrics and Neonatology Izhevsk State Medical Academy 281, Kommunarov Str., Izhevsk, 426034, Russian Federation nabonid1@yandex.ru 